EGU21-14924

https://doi.org/10.5194/egusphere-egu21-14924

EGU General Assembly 2021

(c) Author(s) 2021. This work is distributed under

the Creative Commons Attribution 4.0 License.

\title{
Plate kinematic relationship between the Tyrrhenian basin and the Apennine chain (Central Mediterranean)
}

\author{
Pietro Paolo Pierantoni ${ }^{1}$, Giulia Penza ${ }^{1}$, Chiara Macchiavellii ${ }^{2}$, Antonio Schettino ${ }^{1}$, and Eugenio \\ Turco $^{1}$ \\ ${ }^{1}$ University of Camerino, School of Science and Technology, Geology Division, Camerino, Italy \\ (pietropaolo.pierantoni@unicam.it) \\ ${ }^{2}$ Group of Dynamics of the Lithosphere (GDL), Geosciences Barcelona, Geo3Bcn - CSIC, Lluís Solé Sabarís s/n, 08028 \\ Barcelona, Spain
}

The fragmentation of the Adriatic plate and the sinking of the remnant Alpine Tethys and Ionian lithosphere give rise to passive subduction processes that, together with the collision of the African and European plates, characterize the Central Mediterranean area.

Circum - Mediterranean mountain ranges and Alboran, Balearic, Tyrrhenian and Hellenic back-arc basins are formed in this complex deformation system.

The evolution of the geodynamic processes that guided the opening of the Tyrrhenian basin and the contemporary formation of the Apennine chain are described in this work using the plate kinematics technique.

The study area has been divided into polygons (crustal blocks of microplates) after careful observation of the regional structures. The polygons are distinguished on the basis of the direction of the Tyrrhenian extension and the boundaries between them coincide with the large structures that characterize the Tyrrhenian-Apennine area.

The Tyrrhenian extension directions are indicators of the Euler poles of the individual polygons, in the Sardo-Corso block reference frame. The velocity ratios were determined by the slip vectors of the structures (plate boundaries) that separates the polygons. The rotation time and angle are determined respectively: using the stratigraphic records of the syn-rift sequences and comparing the crustal balance with the speed ratios.

At the end including the new kinematic framework in the global rotation model we were able to reconstruct the tectonic evolution of the central Mediterranean during the opening of the Tyrrhenian basin. 